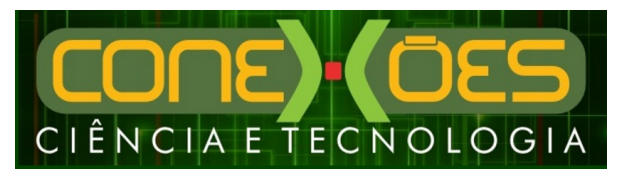
JAGUARIBE - CE

\title{
OS IMPACTOS DO PROGRAMA ALFABETIZAÇÃO NA IDADE CERTA - PAIC, NA ALFABETIZAÇÃO DAS CRIANÇAS DE JAGUARIBE - CE
}

\author{
Maria Efigênia Alves Moreira, José Ronaldo Ribeiro da Silva, \\ ILEANE OliVEIRA BARRos, LuIZA MARIA VIEIRA DE LIMA \\ Instituto Federal de Educação, Ciência e Tecnologia do Ceará - IFCE

<efigenia.alves@ifce.edu.br>.<ronaldrsjr@gmail.com> \\ <ileane.barros@ifce.edu.br>.<luiza.lima@ifce.edu.br>
}

DOI: 10.21439/conexoes.v11i4.1001

\begin{abstract}
Resumo. Este artigo tem como objetivo analisar os impactos do Programa Alfabetização na Idade Certa PAIC, na alfabetização das crianças do município de Jaguaribe-CE, considerando o ano de 2007, quando ainda não existia o Programa, até o ano de 2014. O Programa Alfabetização na Idade Certa - PAIC tornou-se uma política pública no Estado do Ceará com resultados positivos comprovados, através de avaliações externas, e inspirou o Pacto Nacional de Alfabetização na Idade Certa - PNAIC. O referido trabalho foi uma pesquisa qualitativa e quantitativa, em que a metodologia utilizada foi a pesquisa bibliográfica e documental, como o Regime de colaboração para a garantia do direito à aprendizagem, elaborado pela Secretaria da Educação do Estado e utilizado como fonte para a compreensão do funcionamento do Programa e coleta de dados estatísticos de alfabetização, o que possibilitou a comparação de resultados. Sobre a alfabetização em Jaguaribe, foi realizado um levantamento estatístico sobre o processo de avaliação externa a partir de 2007 , sendo possível perceber os avanços na alfabetização. O trabalho consistiu em apresentar e discutir a situação da alfabetização das crianças do Estado e principalmente de Jaguaribe, antes e depois do PAIC. Para tanto, foi apresentado o contexto de surgimento do Programa, seus objetivos, sua estruturação e estratégias de implementação nos municípios cearenses. A análise do processo de alfabetização ao longo desses anos mencionados mostrou que o processo de alfabetização não é um ato isolado.
\end{abstract}

Palavras-chaves: Alfabetização. Criança. Avaliação. Escola.

\begin{abstract}
This article aims to analyze the impact of the Literacy in the Right Age Program (PAIC), in the literacy of children in the city of Jaguaribe-CE, Brazil, considering the year of 2007, when the program had not begun until the year 2014. The Literacy in the Right Age Program (PAIC) became a public policy in the State of Ceará, with proven positive results through external evaluations, and inspired the National Pact of Literacy in the Right Age (PNAIC). This work is a qualitative and quantitative research and the used methodology was bibliographic and documentary research, as the collaborative arrangements to guarantee the right to learn, prepared by the State Department of Education and used as a source for understanding the operation of the program and collection of statistical literacy data, which enabled the comparison of results. On literacy in Jaguaribe, it was conducted a statistical survey of the external evaluation process from 2007, and you can see the advances in literacy. The work presents and discusses the situation of literacy in the State of Ceará, especially in the city of Jaguaribe, before and after the PAIC. To that end, the context of emergence of the Program was presented as well as its objectives, structure and implementation strategies in the cities of Ceará. Analysis of the literacy process over the mentioned years showed that the literacy process is not an isolated act.
\end{abstract}

Keywords: Literacy. Child. Evaluation. School. 


\section{INTRODUÇÃO}

O presente trabalho apresenta o Programa Alfabetização na Idade Certa - PAIC e analisa os impactos na alfabetização das crianças do município de Jaguaribe-CE, uma política pública educacional, que surgiu no estado do Ceará, abrangendo todos os municípios cearenses e que serviu de referência para a elaboração e implementação do Pacto Nacional pela Alfabetização na Idade Certa - PNAIC.

Quando pensamos em política pública, pensamos em direitos e em coletividade. Direitos porque nas sociedades de Estado, são instituídos códigos de condutas e bem estar social, em que os membros são regidos sob determinadas normas e têm garantias de certos benefícios, como educação. Esses benefícios se constituem como direitos, uma vez que o Estado exige de cada cidadão uma parcela financeira, que deverá ser convertida em melhoramentos sociais; coletividade porque os benefícios não devem ter caráter pessoal, mas atender a um coletivo.

Uma política pública nasce a partir dos anseios de uma determinada comunidade/sociedade ou da percepção do Estado frente a um problema social, que deve ser sanado. A partir de então, é elaborado todo um esboço técnico de ideias, aplicabilidade e resultados a serem alcançados. Além disso, exige-se todo um trabalho de implementação, acompanhamento e avaliação.

Uma política pública para ser efetivada, envolve diferentes esferas sociais governamentais e não governamentais, apoio técnico e logístico para descentralizar e fazer a política caminhar. É necessário, portanto, comprometimento pessoal, institucional e disponibilização financeira para o planejamento, execução, monitoramento e avaliação. Toda política pública precisa ser analisada quanto a sua efetividade e contribuição, visto que há investimentos públicos envolvidos que precisam dar um retorno, para analisar se vale a pena ou não continuar com determinadas ações. De acordo com Souza (2006) p.22

O pressuposto analítico que regeu a constituição e a consolidação dos estudos sobre políticas públicas é o de que, em democracias estáveis, aquilo que o governo faz ou deixa de fazer é passível de ser (a) formulado cientificamente e (b) analisado por pesquisadores independentes.

Ao elaborar uma retrospectiva sobre a área denominada de Políticas Públicas, a autora analisa o que cabe ao governo, especificamente, caracterizando suas ações com base nos dois critérios apresentados, que são a capacidade de serem "formuladas cientificamente" e serem "analisadas por pesquisadores" de diferentes áreas. Neste aspecto, a autora delimita a ação governamental enquanto atividade concreta, mensurável e demonstrável.

No que se refere especificamente às políticas públicas ligadas à área da educação, a importância de suas implementações, análises e discussões se fazem mais urgentes, dadas as condições sócio-históricas do assunto no Brasil. Essa é uma preocupação que aflige um elevado número de pensadores, como Castro, que aborda o tema com as seguintes palavras:

\footnotetext{
O Brasil, apesar de seu grande potencial, pode ficar para trás na economia mundial. Sem melhor ensino público, nossas instituições democráticas ficarão fracas e ineficientes, com nossa classe política aproveitando da corrupção e paralisia que afligem nosso Congresso, Judiciário e nossos governos federal, estaduais e municipais. Sem qualidade no ensino público, teremos dificuldade de diminuir as desigualdades sociais e promover o desenvolvimento tecnológico para competir com os países mais avançados (CASTRO 2007 p. 03).
}

O objetivo desse trabalho é analisar os impactos do Programa Alfabetização na Idade Certa - PAIC na alfabetização das crianças no município de Jaguaribe-CE, seu contexto de surgimento, os problemas enfrentados, a implementação da proposta, sua estruturação e os impactos sociais, através das avaliações feitas dentro da própria política de alfabetização de crianças. Serão analisados documentos que apresentam a alfabetização das crianças jaguaribanas a partir de 2007, quando o Programa ainda não existia, até 2014, último resultado apresentado. Assim, será possível comparar dados e perceber os impactos do referido Programa.

\section{METODOLOGIA}

Essa pesquisa é qualitativa, visto que teve caráter exploratório e buscou aspectos subjetivos, percepções, entendimentos e interpretação de contextos históricos. É também quantitativa, uma vez que foram quantificados e comparados resultados de dados estatísticos.

O método utilizado foi o bibliográfico, em que foi coletado referencial teórico publicado sobre a alfabetização e o letramento. Foi utilizada também a pesquisa documental, com levantamento de dados sobre a situação da alfabetização no estado do Ceará e especialmente em Jaguaribe e relatórios institucionais sobre a configuração do Programa Alfabetização na Idade Certa - PAIC.

Foi realizado um trabalho de pesquisa dos resultados de alfabetização das crianças do estado do Ceará, de um modo geral, com foco no município de Jaguaribe, considerando todos os anos em que ele foi implantado e o ano anterior. No decorrer do trabalho, serão 
apresentados gráficos para uma melhor compreensão da situação de alfabetização a partir do ano de 2007. Dessa forma a comparação de resultados que será apresentada será de melhor entendimento. Em seguida foi feita a análise dos resultados e as considerações finais.

A pesquisa foi baseada em teóricos que abordam a questão da alfabetização e do letramento, como Ferreiro (2001), Teberosky (2003), Weisz (1999), Soares (2006), Tfouni (1995), Kleiman (1995) e Simonetti (2005). Essa última foi uma das mentoras do material estruturado utilizado pelas turmas de primeiro e segundo ano, séries que pertencem ao ciclo básico de alfabetização.

Para desenvolver a pesquisa, o primeiro passo foi buscar autores que pudessem contribuir com a abordagem da alfabetização e o letramento, considerando seus processos. Em seguida foram realizadas consultas aos documentos oficiais que explicitam o Programa Alfabetização na Idade Certa - PAIC, explicando sua estrutura e funcionamento e quais estratégias foram encontradas para atender a aspectos ligados direta ou indiretamente à alfabetização e que incide sobre ela.

Por último, foram consultados relatórios e outros documentos que apresentam os resultados das avaliações externas, para elaboração de gráficos com esses resultados e análises e interpretações a partir dos mesmos.

\section{RESULTADOS E DISCUSSÃO}

Podemos dizer que o Programa Alfabetização na Idade Certa - PAIC teve origem em 2004, sem pretensões de política pública, com pequena abrangência e sem ter ainda uma estruturação definida. Foi a partir do Comitê Cearense para a Eliminação do Analfabetismo Escolar, instituído em 2004, através da Assembleia Legislativa, em parceria com outras instituições como o Fundo das Nações Unidas para a Infância - UNICEF e universidades, que o Programa Alfabetização na Idade Certa PAIC começou a se configurar.

O referido Comitê tinha o objetivo de apresentar a situação de analfabetismo de crianças no estado do Ceará e elaborar propostas de correção, com o apoio de várias instituições que pudessem contribuir com essa causa social.

Para apresentar os resultados da pesquisa, o Comitê para Eliminação do Analfabetismo Escolar realizou seminários em todo o estado, evidenciando a situação do analfabetismo. Esse trabalho serviu de reflexão e tomada de decisão frente ao problema que atingia muitas crianças cearenses, independentemente da localização geográfica.
Uma avaliação amostral feita em 2004 pelo Comitê Cearense para a Eliminação do Analfabetismo Escolar apresentou dados alarmantes de analfabetismo de crianças. Foram avaliados os níveis de leitura, escrita e compreensão de textos de oito mil alunos da $2^{\mathrm{a}}$ série do Ensino Fundamental, de duzentas e cinquenta escolas situadas em quarenta e oito municípios (SEDUC, 2012). Os resultados exigiam uma atitude política emergente para melhorar a educação das crianças no estado. O município de Jaguaribe não foi contemplado com essa avaliação.

De acordo com o Regime de Colaboração para a Garantia do Direito à Aprendizagem da SEDUC (2012, p. 19): "das oito mil crianças avaliadas, $39 \%$ não leram o texto; $15 \%$ leram muito mal, soletrando e sem compreender; $31 \%$ leram com dificuldade e compreenderam parcialmente e apenas $15 \%$ leram e compreenderam".

Este olhar estatístico mostrava que as escolas não estavam fazendo muito sentido na vida das crianças, dessa forma, não estavam cumprindo a sua função social, nem no aspecto mais básico, que é ensinar o código linguístico, instrumento para aquisição de outros saberes e imersão social.

Somado a isso, o resultado mostrava outras facetas sociais. Uma delas é que as universidades não estavam formando professores alfabetizadores, mesmo sendo formação para docentes, mas a estrutura curricular não possibilitava uma formação adequada desse profissional, visto que ele não estava conseguindo alfabetizar.

Outro problema que ficou visível diz respeito à metodologia utilizada em sala de aula, quer seja por deficiência na formação, quer seja por ausência de materiais didático-pedagógicos adequados. A pesquisa mostrou que a maioria dos professores não tinha metodologia para alfabetizar, desperdiçavam o tempo pedagógico com atividades que não contribuíam para a aprendizagem e abusavam das cópias no quadro, como forma de ocupar o tempo das crianças e mantê-las quietas.

Essa realidade gerava outros problemas, como constantes evasões no período letivo, distorção idade-série e abandono escolar. Outras crianças chegavam às séries mais avançadas sem a competência necessária, convergindo para o analfabetismo funcional. Dessa forma, tendo a clareza dos fatos e suas variantes, foram-se delineando os caminhos que deveriam ser percorridos, visto o grande problema do analfabetismo de crianças cearenses.

O Programa Alfabetização na Idade Certa - PAIC não surgiu enquanto política pública ligada diretamente ao Estado. Apropriando-se dos resultados do Comitê, 
a Associação dos Municípios do Estado do Ceará APRECE e a União Nacional dos Dirigentes Municipais de Educação - UNDIME, criaram o PAIC, com o apoio técnico e financeiro do Unicef. O objetivo era apoiar os municípios na melhoria da qualidade do ensino da leitura nas séries iniciais do ensino fundamental, (SEDUC, 2012), considerando diversos aspectos, como gestão educativa, formação docente e avaliação, por exemplo.

O Programa Alfabetização na Idade Certa - PAIC teve dois momentos de concepção depois que foi "adotado" pelo governo do Estado. A primeira fase envolveu cinquenta e seis municípios, entre os anos de 2005 e 2006. A segunda fase teve início em 2007, quando o então governo do Estado se empenhou em transformar a situação diagnosticada pelo Comitê Cearense em política pública, tornando-a uma das prioridades de gestão.

A Secretaria da Educação Básica - SEDUC assumiu a execução da proposta do PAIC, em cooperação com os municípios e apoio de outras instituições. No âmbito da SEDUC foi instituída a Coordenadoria de Cooperação com os Municípios - COPEM, com o objetivo de facilitar a operacionalização de todo processo do Programa. Nas Coordenadorias Regionais de Desenvolvimento da Educação - CREDEs foi criada uma equipe para acompanhar a situação a nível de região. No que se refere aos municípios, foram estabelecidas equipes para operacionalização e acompanhamento do Programa, em articulação com a CREDEs.

O Programa Alfabetização na Idade Certa - PAIC foi estruturado em cinco eixos: Gestão da Educação, Avaliação Externa, Alfabetização, Formação do Leitor e Educação Infantil. É uma política que atua numa perspectiva sistêmica, ou seja, trabalha a partir de um leque de metas e ações articuladas e contínuas. Cada eixo tem suas especificidades, mas todos convergindo para melhorar a qualidade da alfabetização. A estruturação dos eixos possibilitou um trabalho com focos diferenciados, mas integrados, alterando a concepção de gestão e acompanhamento que se desenvolvia até então.

O Eixo de Gestão Municipal de Educação, como o próprio nome sugere, fomenta ações específicas de gestão, com abrangência e garantia de direitos. Dentre os objetivos desse eixo está, de acordo com a SEDUC (2012) p. 76:

[...] redução do abandono e evasão escolar; atendimento a cem por cento de crianças em idade escolar; correção de fluxo escolar; nucleação de escolas para facilitar a gestão; definição de critérios técnicos para o processo de seleção de gestores; estabelecimento de políticas de formação de professores; definição de critérios de contratação de professores focados no mérito.
Diante dos poucos objetivos expostos, foi possível perceber a abrangência e responsabilidade desse eixo, que acaba por instalar no município o princípio de uma gestão mais democrática, ao selecionar gestores por competência, por exemplo.

$\mathrm{O}$ eixo de Avaliação externa, ainda segundo a SEDUC (2012, p. 77), tem como objetivo a "instauração de uma política de avaliação, com imparcialidade e clareza no processo avaliativo". É também responsabilidade desse eixo a estruturação de equipes de avaliação externa na Secretaria Municipal de Educação, bem como acompanhamento e divulgação dos resultados. É através desse eixo que os resultados vão sendo redirecionados, gerando novas ações mais eficazes de ensino e de aprendizagem.

O eixo de Alfabetização demanda muito trabalho formativo. Com o objetivo de alfabetizar cem por cento das crianças, existe toda uma política de fomento de recursos metodológicos e formação docente. Através desse eixo, foi estabelecida uma parceria com universidades no sentido de formação contínua de professores, bem como aquisição de materiais de alfabetização, sob a responsabilidade da pesquisadora Amália Simonetti.

Formação de leitor é um eixo com objetivos de formação de leitores. É através dele que são criados cantinhos de leitura em todas as salas de alfabetização e educação infantil, sendo ampliado posteriormente para o ensino fundamental I. Dentre os objetivos, está o de garantir que cada criança leia, no mínimo, cinco títulos de literatura infantil a cada ano letivo.

Segundo a SEDUC (2012, p. 77), o eixo de Educação Infantil tem como objetivos "ampliar o atendimento de crianças de zero a três anos e atender cem por cento das crianças de quatro e cinco anos de idade", fazendo valer a legislação que garante esse atendimento. Como é possível perceber, os eixos são diversos, mas se integram no que diz respeito ao objetivo geral comum, que é alfabetizar na idade certa.

Quando o Programa Alfabetização na Idade Certa - PAIC foi adotado pelo Estado como política pública, algumas estratégias foram traçadas, de modo que todos os municípios pudessem aderir à proposta. Um dos mecanismos foi vincular a distribuição do Imposto sobre Circulação de Mercadorias e Serviços - ICMS a indicadores municipais, visto que o ICMS é recolhido e repassado aos municípios pelo Estado. Como o imposto referido está entre os principais recursos recebidos pelos municípios, isso "forçou" não apenas a adesão, como também a busca por resultados. Foi uma ação que alterou a legislação e impulsionou o Programa.

Somado a isso, foi instituído o Prêmio Escola Nota 
Dez, que segundo a SEDUC (2012, p. 87), tem o objetivo de "fortalecer, valorizar e ampliar o trabalho que vem sendo empreendido pelos municípios e escolas em relação à alfabetização de crianças". Esse prêmio em dinheiro é direcionado às escolas públicas que apresentarem os melhores resultados em alfabetização, mostrado através do Índice de Desempenho Escolar - Alfabetização (IDEA-Alfa). No entanto, existem vários critérios para alcançar o Prêmio, dentre eles o número de alunos por sala e nota mínima obtida. O Prêmio é outorgado em cerimônia pública, com a presença de muitas autoridades, o que dá uma visibilidade ao município que consegue atingir o patamar desejado.

As avaliações são realizadas externamente ao município e os resultados são tabulados, analisados e divulgados para os municípios, gerando novas ações. Quando um determinado município apresenta resultados muito inferiores ao que se desejava, a SEDUC e a CREDE implementam ações mais focadas e com prazos menores estabelecidos, no sentido de fortalecer as ações municipais e gerar resultados positivos. A figura 1 abaixo é demonstrativa da metodologia do programa no Estado do Ceará.

Figura 1: Alfabetização no Estado do Ceará em 2014 - SPAECEAlfa.

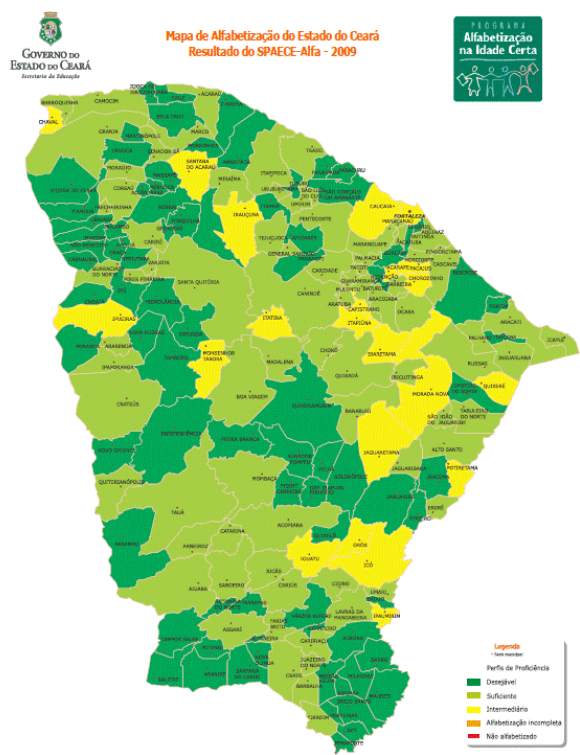

Fonte: Spaece-Alfa (2009)

Os resultados obtidos nas avaliações de desempenho do Spaece-Alfa foram simbolicamente representados por cores, para melhor visualização, considerando perfis de proficiência. $\mathrm{O}$ vermelho representa o não alfabetizado (0 a 75 pontos); laranja representa alfabeti- zação incompleta (75 a 100 pontos); o amarelo representa o nível intermediário (100 a 125 pontos); a cor verde clara mostra o nível suficiente ( 125 a 150 pontos) e por fim o verde escuro, que representa o nível desejável, os que atingem acima de 150 pontos (SEDUC. 2012).

No início de cada ano, a SEDUC realiza uma avaliação em todos os municípios com objetivo de diagnosticar a situação e direcionar ações. Essa avaliação não contabiliza para definir o repasse do ICMS ou o Prêmio Escola Nota Dez. Tem caráter diagnóstico. De posse dos resultados, cada município intensifica ações de acordo com o que foi apresentado como fragilidade. E no final de cada ano, a SEDUC realiza a avaliação do Spaece-Alfa, que irá gerar o Índice de Desempenho Escolar - Alfabetização (IDEA-Alfa). Esse resultado é usado para definir o montante do ICMS que será repassado aos municípios, bem como a entrega do Prêmio Escola Nota Dez, às escolas que apresentarem os melhores resultados.

No ano de 2007, quando o estado adotou a proposta do Programa Alfabetização na Idade Certa - PAIC, os resultados da avaliação do Spaece-Alfa demostravam que os alunos do segundo ano do ensino fundamental da rede pública não conseguiam ler ou estavam em processo inicial de alfabetização. Para se ter uma ideia da gravidade do problema, 47,5\% dos alunos estavam na situação de não-alfabetizados. Dos 184 municípios cearenses, apenas quatorze deles estavam no nível desejável (SEDUC, 2012).

$\mathrm{O}$ ano de 2008 representou o primeiro ano das intervenções nas escolas públicas. Nesse momento, começam as formações docentes, o apoio técnico às gestões municipais, o fornecimento de material didáticopedagógico, sensibilização das famílias e comunidades da situação de alfabetização. Todo esse esforço gerou resultados positivos, em que o índice de nãoalfabetizados saiu de $47,5 \%$ para $36,2 \%$. Para um primeiro ano de implementação do Programa, os resultados foram muito significativos.

Em 2009, foi instituído pelo governo do estado o Prêmio Escola Nota Dez, tendo como base os resultados de 2008, com objetivo de premiar até cento e cinquenta escolas com os melhores resultados de alfabetização. Foi também nesse ano que o governo vinculou a distribuição do ICMS aos indicadores de qualidade na educação, saúde e meio ambiente, considerando um peso maior aos indicadores educacionais (SEDUC, 2012).

Os percentuais de não alfabetizados continuaram a ser reduzidos, caindo de $36,2 \%$ para $28,3 \%$, mostrando a eficácia do Programa. Com a continuação da política 
do PAIC, houve maior redução no percentual de alunos no nível não alfabetizados, passando de $28,3 \%$ para $16,3 \%$. Ou seja, $70,7 \%$ dos alunos já se encontravam no nível desejável de alfabetização, o que representava uma leitura proficiente, com competência de compreensão, reconhecimento de assunto principal de um texto e outros elementos que caracterizam o nível suficiente e desejável.

E assim as ações foram mantidas de forma integrada e os resultados sempre crescentes. Prova disso foi o fato de os alunos não alfabetizados terem saído de 47,5\% em 2007 para 8,7\% em 2012. Em 2013 o índice de proficiência do $2^{\circ}$ ano estava em 165,1, ou seja, Desejável. E em 2014 foi de 174,3.

No caso do município de Jaguaribe, localizado a $300 \mathrm{~km}$ da capital do Ceará, com aproximadamente 34 mil habitantes (IBGE, 2010), em 2007 estava no nível de Alfabetização Incompleta (cor amarela). De 845 alunos matriculados no $2^{\circ}$ ano, 79,6\% fizeram a avaliação, ou seja, 673 alunos. Destes 275 estavam nãoalfabetizados, um percentual bastante significativo de analfabetos; 88 alunos com alfabetização incompleta; 79 estavam no nível Intermediário de alfabetização; 61 no nível Suficiente e 170 alunos no nível Desejável de proficiência. Diante desse quadro, houve passividade da secretaria municipal de educação. Talvez por falta de uma cultura de avaliação e de acompanhamento pedagógico, a situação de alfabetização das crianças piorou no ano seguinte.

No ano 2008 o município caiu do nível Intermediário para Alfabetização Incompleta, com um nível de proficiência de 99,9 (cor laranja). De 672 alunos matriculados no $2^{\circ}$ ano, 606 participaram da avaliação $(90,2 \%)$. Desse total, 197 estavam no nível Não alfabetizados; 131 alunos com Alfabetização Incompleta; 122 no nível Intermediário; 85 no nível Suficiente e apenas 11,8\% dos alunos no nível Desejável. Ou seja, enquanto 71 alunos sabiam ler e escrever, 328 não tinham competências de leitura e escrita, somando os analfabetos e os com alfabetização incompleta.

Feito um trabalho de mobilização e tomada de decisão, com formação docente, acompanhamento pedagógico e avaliações diagnósticas, somados a outras ações de reforço escolar e de incentivo à leitura, em 2009 o município de Jaguaribe deu um salto na alfabetização das crianças, saindo de um índice de proficiência de 99,9 para 157,3, ou seja, de Alfabetização Incompleta para o nível Desejável. E com uma consciência do trabalho de alfabetizar, os anos seguintes foram só crescimento. Em 2013, de 412 alunos previstos para realizar a prova, 422 fizeram, atingindo 102,4\% de participação.
Esse total é justificado pelo número de alunos que entrou na escola depois do Senso escolar fechado. Nesse mesmo ano, apenas $1,2 \%$ dos alunos não estavam alfabetizados ( 5 alunos), enquanto 294 alunos estavam plenamente alfabetizados (nível Desejável). Em 2014, o município atingiu 169,1 de proficiência, conforme gráfico 1 abaixo:

Gráfico 1: Resultados do município de Jaguaribe no Spaece-Alfa entre 2007 e 2014.

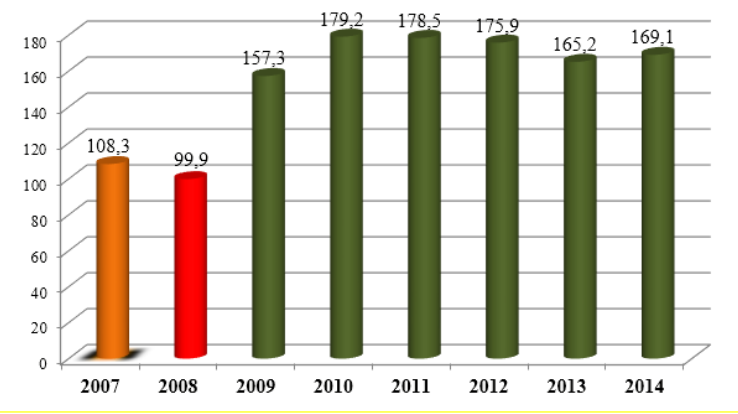

Fonte: SEDUC-CE (2015).

Manter-se no nível de proficiência Desejável, ou seja, alfabetizando as crianças na idade correta é um desafio. As ações que convergem para esse resultado devem ser mantidas. É direito das crianças e obrigação do Estado, visto que implica em um imperativo das sociedades democráticas.

\section{CONCLUSÃO}

O Programa Alfabetização na Idade Certa - PAIC trouxe um resultado muito significativo para a alfabetização das crianças cearenses e especificamente jaguaribanas. A abrangência do Programa mostra que o processo de alfabetização não pode acontecer de forma isolada, mas muitas ações devem ser integradas para que esse direito seja garantido. Pouco a pouco vemos ser implantada uma cultura alfabetizadora e de comprometimento coletivo.

Diferente de antes, há uma preocupação quanto aos resultados, que são numéricos, mas implicam em contextos de vida. Os resultados também mostram que o Programa justifica os investimentos que são feitos para a sua realização. Além disso, vale ressaltar que a metodologia do PAIC no Estado do Ceará serviu de base para o desenvolvimento da ação nacional ensejada pelo PNAIC, o que torna o Ceará um centro irradiador de boas práticas de planejamento em educação. 


\section{REFERÊNCIAS}

CASTRO, M. H. G. d. Problemas institucionais

do ensino público. 2007. Disponível em:

<http://pt.braudel.org.br/publicacoes/braudel-papers/

downloads/portugues/bp42_pt.pdf>. Acesso em:

$10 / 12 / 2015$.

FERREIRO, E. Reflexões sobre alfabetização. 24,

Ed.São Paulo: Cortez, 2001.

FRIGOTTO, G. Educação e a Crise do Capitalismo Real. São Paulo: Cortez, 1995.

KLEIMAN, A. Modelos de letramento e a prática de alfabetização na escola. In: KLEIMAN, A. (Ed.). Os significados do letramento. Campinas, S.P: Mercado de Letras, 1995. p. 15-61. 294p.

. Preciso "ensinar" o letramento? Não basta ensinar a ler e a escrever? Campinas: Cefiel Unicamp; MEC, 2005. 60p.

SEDUC. Regime de colaboração para a garantia do direito à aprendizagem: o Programa Alfabetização na Idade Certa (PAIC) no Ceará / Secretaria da Educação /(unicef). Fortaleza: , 2012. Secretaria da Educação do Ceará, Fundo das Nações Unidas para a Infância.

SIMONETTI, A. O desafio de alfabetizar e letrar. Fortaleza: Edições Livro Técnico, 2005. 208p.

SOARES, M. Letramento: um tema em três gêneros. 2. ed. Belo Horizonte: Autêntica, 2006.

SOUZA, C. Políticas públicas: uma revisão da literatura. Sociologias, Porto Alegre, ano 8, n. 16, p. 20-45, jul/dez 2006.

TEBEROSKY, A. Compreensão de leitura: a língua como procedimento. Tradução de Fátima Murad. Porto Alegre: Artmed, 2003.

TFOUNI, L. V. Letramento e alfabetização. São Paulo: Cortez, 1995.

WEISZ, T. O diálogo entre o ensino e a aprendizagem. São Paulo: Ática, 1999. 